\title{
TEXT-BOOK OF PATHOLOGY
}

\section{By RoBert Muir.}

3rd Edition, 1933. pp. 935. Published by Edward Arnold. Price, 35/- net.

Students of pathology, whether pre- or post-graduate, will welcome the thirdedition of this well known and popular text-book. Changes have been made both in the contents of the book and slightly so in its format.

It is printed now on slightly glazed paper on which the many illustrations shew up to great advantage, whilst, despite the changes which have been made and the new matter which has been added, the number of pages has only been increased by about eighty.

In the preface to the First Edition Professor Muir wrote-“" Whilst the work deals chiefly with the structural changes in disease, I have made it my object also to shew the bearing of these on disturbances of function, as studied by the clinician, and to incorporate the principal results of experimental and chemical research."

How well these objects have been attained will be evident to those who study the chapters on, for instance, the liver, the kidneys and the heart.

For this reason if for no other, Professor Muir's book will make a wider appeal than will those which restrict themselves to the description of morbid changes and in which the effects of such changes on the function of organs as revealed by clinical medicine are neglected.

The opening chapters on general pathology, such as those on nutrition, inflammation and repair, are extremely lucid and require to be mastered before the student proceeds to their special application to the various organs.

In the chapter on the heart the recent work on the polygraph and its use in the diagnosis of morbid changes in that organ is described and an explanation of various tracings as an indication of the anatomical changes in the heart is given.

The chapter on kidney disease is comprehensive and up-to-date, but although a reference is made to the researches of Russell, Gray and others, Professor Muir does not adopt their classifications but retains the more familiar arrangement based on the particular part of the kidney, primarily involved, that is, whether glomerular, tubular or vascular. The effect of these changes on the function of the kidney is clearly set forth and their bearing on the problems of renal insufficiency, uræmia, œdema and cardio-vascular change is just what the clinician wants to know. This determination to illuminate the problems of the bed side by light gained at the post-mortem table will be appreciated both by the student and the practitioner.

In other departments also the book has been brought right up to date : take for instance the recent work on vitamin deficiences; Bailey and Cushing's classification of cerebral tumours; Collip's work on the parathyroid; that of Rous and Gye on the problems of cancer; the cultivation of tumour tissues in vitro; the transmission of the virus of lymphadenoma, all of which receive adequate recognition.

A separate chapter has been devoted to the endocrine glands and the diseases associated with them thus placing this important group of organs into clear perspective and we think the same might have been done for the group of deficiency diseases which are now scattered through the book and are not easy to envisage in their mutual relationship.

Syphilis and the venereal diseases in general receive less attention than their importance justifies and we find no reference to the recently recognised venereal disease known as Lymphogranuloma inguinale. One or two other minor omissions which occur to one in passing are the infections due to $\mathrm{Br}$ abortus; the influence of vitamin deficiency on the incidence of stone ; the existence of a type of ulcerative colitis unconnected with tropical disease which is of severe and often fatal character; and the frequency of polyposis of the rectum as a precursor of cancer.

Such minor criticisms do nothing to detract from the excellence of this edition which reaches an even'higher standard of usefulness than before and which can be confidently recommended to the student and postgraduate as one of the best balanced books on Pathology in our language. 